\title{
Menino ou Menina? Gênero e Desenvolvimento Infantil ${ }^{1}$
}

\section{Boy or Girl? Gender and Child Development}

\author{
Marcus Aurélio Ribeiro MANHÃES*
}

RESUMO

Objetiva-se, por meio da pesquisa, identificar a importância das relações de gênero no desenvolvimento infantil. Numa pequena cidade do sertão pernambucano, busca-se a livre expressão de crianças no contexto social mais amplo, extrapolando-se os limites do lar e das relações parentais. Quanto aos subsídios teóricos do trabalho, articulam-se estudos de gênero - diferenciados de sexo - especialmente os de Nancy Chodorow com a teoria de desenvolvimento infantil freudiana. Na pesquisa, inserida na metodologia qualitativa, usamse estratégias de filmagens, entrevistas e interações sociais espontâneas como meios de acessar crianças, entre 2 e 7 anos de idade, em suas atividades cotidianas de brincadeiras de rua ou em situações educacionais de creches e escolas. Norteia-se a elaboração dos dados coletados pela leitura pontual das filmagens, em cuja organização consideram-se idade, gênero e as interações entre meninos e meninas. Como resultados, identifica-se e confirmase a diferenciação de comportamento entre os gêneros, a qual é caracterizada de acordo com a idade dos envolvidos, e constata-se que essa diferenciação pode ser estimulada por alguns valores ou práticas sociais, vinculados pela prática pedagógica. Observando-se atentamente a relação das crianças com as figuras adultas, verifica-se os efeitos de identificação secundária. Conclui-se que é importante a continuidade de estudos que correlacionem gênero e desenvolvimento infantil, seja para aspectos clínicos ou educacionais. Adicionalmente, recomenda-se uma reaproximação das teorias psicodinâmicas com o estudo das questões de gênero, na busca de subsídios para a educação.

Palavras-chave: gênero - desenvolvimento infantil - sexualidade - educação.

\section{ABSTRACT}

It aims through the research, to identify the importance of the relations of gender on

\footnotetext{
${ }^{1}$ Baseado na dissertação de mestrado de mesmo título, sob orientação da Profa. Dra. Isaura Rocha Figueiredo Guimarães - Faculdade de Educação UNICAMP, Campinas - SP, fev. 2004. * Mestre em Educação pela UNICAMP. Pesquisador em Educação e Desenvolvimento Humano. E-mail:mmanha@ig.com.br
}

Olhar de professor, Ponta Grossa, 7(1): 85-101, 2004. 
child development. In a small town of Pernambuco, it searches the children's free expression in the wider social context, beyond the home limits and the parental relations. About the theoretical subsidy of the work, it articulates the gender studies - differently of sex - specially from Nancy Chodorw with Freud's child development theory. In the research, inserted into the qualitative methodology, it has been utilized filming strategies, interviews and spontaneous social interactions as way to access children, between two and seven years old, in their daily activities of street play or in educational situations of crèche and schools. It leads the elaboration of collected data by the punctual reading of filming, in which organization it is considered age, gender and the interactions between boys and girls. As results, it is identified and confirmed the differentiation of behaviors of between gender, which is characterized according to the age of the involved and it is ascertained this differentiation can be stimulated by some values or social practices, linked by pedagogical practice. To observe closely the children's relation with the adults people, it is verified the effects of secondary identification. It has been concluded that it is important the continuity of studies those correlate gender and child development, being to clinical or educational aspects. To add, it is recommended a re-approximation of psychodynamics theory with the studies of gender perspectives, searching elements to education.

Key words: gender - child development - sexuality - education.

Despertamos para a questão de gênero quando lemos pela primeira vez um texto de Isaura Guimarães (1997). Naquela reflexão, ela denunciava a resistência da psicologia a uma compreensão mais ampla da sexualidade humana, destacando os caminhos da criança para compreender o que é homem ou mulher, e já nos indicava compromissos a serem assumidos na elaboração de nossos questionamentos:

Estarão as causas das diferenças comportamentais dos sexos nos hormônios, advindas de uma tipificação sexual inata ou surgem no processo de conformidade às expectativas de papéis sociais, que se incorporam à personalidade pela aprendizagem?
(GUIMARÃES, 1997, p. 41).

Tal questionamento nos levou a pensar em princípios socializadores primários que agem tanto no seio familiar como na sociedade mais ampla. Resgatamos conceitos de Nancy Chodorow (1990), ao propor a compreensão que se estabelece sob a afirmação base de que "gênero é o sexo sociológico". Conforme entendemos, essa concepção de gênero distanciase radicalmente das afirmações estabelecidas naquelas correntes teóricas que se fundamentaram, exclusivamente, nas diferenças de sexos como decorrentes dos fatores biológicos. Agregando a afirmação de Nancy Chodorow, em metáfrase a Isaura Guimarães, compreendemos que tais reflexões englobam constru-

86 Olhar de professor, Ponta Grossa, 7(1): 85-101, 2004. 
ções da cultura e diferenças entre homem e mulher na relação com a organização social, considerando que as implicações sobre determinações de gênero são fruto das relações sociais, passíveis de reprodução em ambiente escolar ou familiar.

Então, nos lançamos sobre implicações de gênero que assumissem importância no desenvolvimento infantil, definindo como problema e objetivo de pesquisa analisar o desenvolvimento da criança em sua correspondência com gênero.

Como já sinalizamos, partimos de Nancy Chodorow que, para justificar sua afirmação base, construiu um diálogo com Sigmund Freud. Assim, definimos o modelo conceitual para o desenvolvimento infantil a partir da teoria freudiana.

Para responder ao problema de pesquisa, questionamos afirmações freudianas, já cristalizadas, pois a teoria freudiana clássica propõe leituras severas para o par macho-castrado, caracterizado de forma valorativa "superior-inferior". Desviando das definições que fazem alusão à dicotomia valorativa, nos concentramos na fundamentação da diferenciação para meninos e meninas que está, principalmente, articulada com a construção mítica do complexo de Édipo.

Nancy Chodorow (1978), em seu questionamento a Freud, apontou falhas na teoria, por negligenciar a ligação entre a sociologia e a psicologia, conjunções nas quais os fenômenos sociais devem afetar o padrão de de- senvolvimento psicológico de um indivíduo.

\section{METODOLOGIA}

Garantindo subsídio às discussões teóricas, decidimos checar as informações em campo, indo ao encontro da sociedade, a fim de esclarecer as inter-relações entre o gênero e o desenvolvimento infantil, atitude que estabeleceu os sujeitos para nosso estudo: crianças de 2 a 7 anos.

Inicialmente, especulávamos uma forma de abordagem às crianças. Ficava evidente que não poderíamos abordá-las na rua, pois em nossa cidade as crianças são tuteladas por adultos, especialmente as mais jovens, que muito nos interessavam. Percebemos que necessitávamos de flexibilidade e de caminhos para considerar nossas próprias impressões no ato da pesquisa. Já considerávamos a diversidade no campo de pesquisa, parcialmente na rua e parcialmente em escolas, ambientes esses em que as crianças puderam ser encontradas entretidas em suas brincadeiras ou tarefas escolares, a fim de serem observadas e analisadas.

Optamos pela pesquisa qualitativa, cuja metodologia se insere em paradigma científico, nos permitindo uma maior aproximação dos sujeitos. Através de González Rey (2000), compreendemos que pesquisas qualitativas em psicologia constituem via de acesso para dimensões do objeto que estão inacessíveis no uso das pes- 
quisas quantitativas.

A demarcação metodológica nos permitiu a interpretação dos fenômenos observados e organizados conforme as leituras teóricas da teoria de desenvolvimento freudiana e proposições de Nancy Chodorow.

Escolhemos pesquisar numa pequena cidade de Pernambuco, Venturosa, onde tínhamos realizado uma experiência anterior e fomos autorizados a acessar dependências escolares, participar de atividades e promover dinâmicas necessárias ao trabalho de pesquisa, com as crianças da faixa etária de nosso interesse.

Venturosa está localizada a 243 km da capital pernambucana, Recife, com acesso pelas rodovias BR 424 e 217, na região do Agreste Setentrional, com uma população estimada no último censo em 13.013 habitantes. A cidade se inscreve na região que é assolada pela seca nordestina.

$\mathrm{Na}$ pesquisa qualitativa, as técnicas normalmente utilizadas estão abertas e maleáveis; assim, de modo geral, permitiram o estabelecimento de um vínculo com a criança nos momentos iniciais. Decidimos utilizar o vídeo como meio de registro das situações significativas para a pesquisa.

Observávamos os grupos e, aos poucos, introduzíamos as gravações e depois a reprodução para as crianças. De fato, quando reproduzíamos as gravações, o processo era muito divertido - as crianças ficavam muito felizes ao se identificarem nas imagens.
Planejamos direções para nossa câmara de vídeo tape nos contextos da escola e da rua. Na escola, que entendemos como o campo principal de pesquisa, tínhamos grupos de crianças organizados por faixa etária. Considerávamos que a faixa etária compreendida entre 4 e 7 anos seria ideal para os sujeitos serem observados, pois, segundo as discussões teóricas, poderiam ocorrer fenômenos de resolução do conflito edípico, ou de separação/identificação com a mãe, embora saibamos que não haja correlação precisa entre as fases de desenvolvimento e a idade cronológica.

A rua e as atividades extracurriculares foram entendidas como campo secundário de pesquisa, pela liberdade e flexibilidade das observações. O mundo aberto se apresentava de forma espontânea, não tivemos controle sistemático dos sujeitos. Insistimos numa leitura da realidade, conforme os fatos se mostravam e eram registrados, pois entendíamos que o vídeo coletaria as imagens e cenas e, então, procederíamos à seleção de todas as cenas que julgássemos pertinentes.

Além da pesquisa propriamente na rua, tivemos oportunidade de nos relacionar com crianças que estavam vinculadas a dois projetos distintos: Ciranda da Criança e Programa de Erradicação do Trabalho Infantil PETI. Esses dois grupos tinham características funcionais distintas da educação formal, desenvolvendo atividades extracurriculares, também fora 
da escola. Assim os consideramos distintos das creches, distintos da escola e próximos da rua.

No período compreendido entre 4 e 14 de dezembro de 2001 visitamos diariamente escolas do Município de Venturosa. Tivemos muita colaboração dos 11 professores, dez mulheres e um homem, que eram responsáveis pelas 158 crianças, com faixa etária compreendida entre 2 e 7 anos.

A distribuição de alunos nas creches apresentou $53 \%$ de meninos e $47 \%$ de meninas, com ligeiro predomínio numérico de meninos. Entretanto, ao reconsiderarmos a distribuição em duas faixas etárias, notamos variações expressivas. A faixa de 5 a 7 anos apresentou predomínio numérico significativo de meninas, com $61 \%$; os meninos totalizaram $39 \%$. A faixa etária de 2 a 5 anos apresentou inversão de predomínio, com $65 \%$ de meninos e $35 \%$ de meninas.

o campo secundário, onde dispúnhamos de mínimas oportunidades de intervenções seqüenciais, não pudemos classificar todos os sujeitos com a precisão de idade e, desse modo, apenas generalizamos a distribuição, em que nos deparamos com $60 \%$ de meninas e $40 \%$ de meninos.

Com a revisão do material gravado, pudemos construir uma síntese de atitudes e reações das crianças observadas nas creches, rua e atividades extracurriculares, bem como as atitudes dos (as) professores (as).

O processo de elaboração e seleção desse material pode ser explicado pela ordenação lógica dos dados coletados, a partir do contexto teórico que discutimos, qual seja, buscamos colher os aspectos significativos na realidade para as implicações do gênero no desenvolvimento infantil. Desse modo, as falas e demais expressões dos sujeitos sugerem evidências para categorias de análise do problema que se aglutinaram em torno da idade cronológica das crianças.

Desde os primeiros registros, adotamos e mantivemos comentários que denominamos "Frases para o Imaginário", que se referem a impressões espontâneas que surgiram na mente do pesquisador, quando da revisão do material filmado. Consideramos a importância dessas expressões, pois de forma livre de quaisquer constrangimentos, elas emitem opinião num ponto focal da ocorrência registrada, mesmo que possam denunciar a ação inconsciente do pesquisador e até mesmo julgamento de valor.

Tratamos de nossas imagens-registros em quatro macro etapas que se referem aos seguintes indicadores: faixa etária, gênero, contexto relacional e expressão dos (as) professores (as). Nas faixas etárias, dividimos os registros em três pontos focais que nos dão conta de atitudes e reações dos meninos, das meninas e das atitudes e ações estabelecidas entre meninos e meninas, o que poderíamos denominar de aspectos relacionais, seguindo a nomenclatura utilizada por Georges Boris (2000).

Apresentamos a seguir, exemplos 
das sínteses e comentários dos dados analisados. As "frases do imaginário" estão indicadas entre aspas, para distinção da observação e caracterização da opinião instantânea do pesquisador.

\section{ATITUDES DOS MENINOS}

Em brincadeiras com lego, os meninos constroem: dragão, avião, monstros e super heróis. "Isso é de homem".

Os meninos trazem carrinhos e robôs e monstrinhos. "Ah, de menino".

Nesses itens, podemos notar que o tipo de brinquedo que está disponível aos garotos atraem movimento e ações propostas por tais objetos. Quando utilizamos a palavra ação, realmente estamos destacando movimentos bruscos e velozes, pois assim notamos o desenrolar do brincar com esses objetos que se deslocam no ar, em cenários imaginários, atacando e destruindo inimigos, também imaginários. O super-herói, menino, deslocase de um "hominho" para um avião ou dragão. O objeto comporta-se como uma tela de projeção na qual fantasias de auto-imagem ou de uma figura, quem sabe a paterna, estão projetadas.

\section{ATITUDES DAS MENINAS}

Em brincadeiras com lego, as meninas constroem: pessoas, meninos, meninas, objetos sem de- nominação. "Isso é de menina!" As meninas trazem bonequinhas.

"Somos mamães".

Tais itens nos revelam o interesse das meninas em relação às pessoas. Falando pela negação, as meninas não constroem monstros, não manuseiam armas ou dispositivos para ataque e destruição. A meninas brincam com objetos que imitam figuras humanas. Com as bonecas, exercem afabilidade e maternagem.

\section{ATITUDES COMPARATIVASEN- TRE MENINOS E MENINAS}

Nos grupos espontâneos, formados por crianças com até 3 anos e seis meses, há meninos e meninas. "Somos anjos, não temos sexo".

Nos grupos espontâneos, formados por crianças com mais de 3 anos e seis meses, há separação de gêneros. "Menina para lá e menino para cá”.

$\mathrm{O}$ item referente aos grupos espontâneos formados por crianças mais jovens confirma uma observação anterior, quando notamos um comportamento heterônimo das crianças mais novas. De fato, esses itens estão demarcados pelo limite aproximado de 3 anos e seis meses, que foi o apurado naquela oportunidade. Essa linha demarcatória nos revela que, até por volta desse limite de idade, as crianças estabelecem uma neutralidade quanto à escolha de companheiros por sexo e gênero. A partir de 
determinado desenvolvimento afetivo ou psicológico, a criança passa a estabelecer um comportamento de segregação quanto a gênero e, espontaneamente, coloca-se nos espaços da sala de aula, mesas ou cantos, agrupando-se com os iguais em gênero: meninos e meninas separados.

\section{EXPRESSÃO DOS(AS) PROFESSORES(AS)}

Quanto às ações dos (as) professores(as), destacamos ocorrências significativas em relação aos aspectos educacionais e às diferenças por gênero, seja reforçando comportamentos, seja, no pior dos casos, fornecendo referências que inseriam as crianças no mundo relacional de superiroridade-inferioridade, inadequadas no nosso entender.

De repente ele destrói tudo, né Robson? "Robson você é um terror mesmo!"

As meninas não têm comportamento assim. Só Patrícia. "Mas

Patrícia não é uma menina, então tudo bem”.

Nesses dois itens de observação, entendemos que aquelas professoras reforçavam atitudes negativas. Com a frase "De repente ele destrói tudo, né Robson?" a professora afirma e, ao mesmo tempo, pede uma confirmação do garoto. Do mesmo modo, no item seguinte, quando a professora afirma sobre Patrícia, a está diferenciando do comportamento esperado para as meninas, indica para os meni- nos como eles devem proceder e exclui a menina do mundo feminino.

\section{DISCUSSÃO}

A classificação sexual dos seres humanos em homens e mulheres é uma proposta da biologia que estabelece delimitações e interpretações rigorosas para ambas as classes, desde o início do desenvolvimento dessa área de conhecimento. Assim, tomam-se referências pautadas nos aspectos anatômicos e fisiológicos das diferenças entre os sexos como prioritárias, deixando-se os fatores psicológicos ou subjetivos, os endócrinos e, adicionalmente, aqueles decorrentes das interações sociais fora de considerações.

Para as áreas de educação e psicologia, essa é uma visão reducionista. Entretanto, em breve análise das ciências nos deparamos com tal conceito extrapolado para muitas áreas do saber, socialmente difundido e enraizado culturalmente.

Recorremos ao estudo de Georges Boris (2000) sobre vivências masculinas na contemporaneidade, no qual o autor efetuou análises sobre o homem a partir da categoria de gênero, discutindo as noções de sexo, identidade, condição, subjetividade e papéis masculinos. Neste momento, tomamos sua contribuição para nosso posicionamento crítico em relação à excessiva valorização biológica na conceituação de sexo, e a decorrente conotação de dominância de um sexo 
sobre o outro:

Tradicionalmente, o pensamento ocidental tende a se dividir entre duas abordagens aparentemente distintas da dualidade dos sexos - o modelo da semelhança $e o$ modelo da diferença entre homens e mulheres - mas, em ambos os casos, sempre se buscou afirmar a superioridade do homem, o que justifica sua histórica dominação sobre a mulher. (BORIS, 2000, p. 35).

Contemporaneamente, já podemos nos valer do conceito de gênero para designar os mundos masculino e feminino, superando a estreiteza do conceito sexo. Ao falar em gênero, estamos considerando os efeitos das construções culturais sobre os homens e as mulheres, bem como incorporando ao conceito de sexo a forma como os homens e as mulheres vêem e vivenciam a organização social. De fato, o conceito de gênero trata das relações entre homens e mulheres, de como foram construídas ao longo da história, e de como se apresentam em diferentes lugares.

Georges Boris confirma o que estamos defendendo, ao afirmar:

A noção de gênero, diferentemente da concepção de sexo, mais do que se limitar à referência ao mero exercício da prática sexual, inclui a investigação das atitudes, dos comportamentos, das relações, dos valores, dos estereótipos, dos conceitos e dos preconceitos, que também são soci- al, histórica, política - pois têm caráter ideológico - e culturalmente construídos. (BORIS, 2000, p. 18).

O autor nos alerta para três dimensões essenciais na noção de gênero, às quais devemos estar atentos: a dimensão relacional e as dimensões contextual e histórica, que estabelecem correlação intrínseca entre si.

No conceito relacional de gênero se estabelece que, ainda que o macho e a fêmea possam ter características universais, "não se pode compreender a construção social da masculinidade ou da feminilidade sem referência ao outro pólo relacional". Machos são definidos em relação às fêmeas e vice-versa.

Seguindo a pesquisa intercultural, Nancy Chodorow (1989) sugere que não há diferenças determinantes dos comportamentos de homens e mulheres, mas que muitas das características que normalmente são tidas como próprias de um gênero ou de outro são fruto do modo de diferenciar os machos e as e fêmeas humanas, na cultura específica à qual pertencem.

Nesse percurso, a autora afirma que, em todas as situações de socialização, o socializador primário é uma mulher. Os homens podem ajudar a cuidar das crianças, mas eles têm um compromisso de trabalho em outro lugar, que não o lar. Com as mulheres ocorre exatamente o oposto. Seu compromisso primordial está no lar, no cuidado com os filhos.

Para Nancy Chodorow, surge um 
ponto crítico que diferencia a educação dos meninos: eles devem buscar independência, rejeitando sua própria mãe, conscientemente ou inconscientemente. Isso significa separar-se e distanciar-se do universo feminino. Essa situação seria aprovada e reforçada pelas diferentes instituições culturais que cercam as crianças. Adicionalmente, ao não serem submetidas a essa passagem de separação, as meninas permaneceriam ligadas às mães e ao mundo doméstico, o que redunda em conseqüências diferentes para a identidade de meninos e meninas.

Da mesma forma, seguindo tais afirmações, poderíamos deduzir o porquê da crença de que "a identidade masculina depende apenas dos próprios homens", com o entendimento de que um homem se constrói por si próprio e não em relação ao outro, enquanto que as mulheres crescem direcionadas para o outro, dependentes da aprovação e reprovação externa, ao se construírem. O menino cria barreiras para se diferenciar e bloquear suas expressões em relação ao mundo feminino, numa conquista de independência e afastamento, com expressão do que está aparente em nível consciente. No entanto, para um menino a identificação primária com a mãe e com o feminino jamais será removida de suas impressões mais profundas, mantendo uma dependência indefinida, o que nos aproxima do entendimento da identidade feminina, numa suposta essência em ambos os gêneros, onde meninos e meninas mantêm uma ligação com a figura materna.

Cremos que o cerne de todas as afirmações de Nancy Chodorow seja: Estas considerações sugerem que o centro da identidade de gênero e masculinidade apresentam conflitos para homens, e são organizados como senso masculino de ego e, de certo modo, o centro da identidade de gênero e feminilidade não apresentam conflitos para a mulher. (CHODOROW, 1989, p. 109).

Desde Freud afirma-se, nas etapas de desenvolvimento primárias, que machos não são fêmeas. A essência da identidade de gênero masculina e o senso de masculinidade estão definidos negativamente: o que não é feminino, não é mãe, não é sensível, etc. No modelo masculino encontramos manobras de defesas que elevam o receio das mulheres, o receio de expressar qualquer forma de feminilidade: passividade, carinho, cuidados em relação aos outros e, especialmente, o medo de ser desejado por um homem.

Em oposição, no modelo de desenvolvimento feminino não se definem as fêmeas enquanto não-machos. A essência da identidade de gênero feminina e o senso de feminilidade são definidos afirmativamente, ou positivamente, como o que é feminino, ou como é mãe - a figura materna tende ao universo feminino. A menina não é definida como nãomenino, não-pai, pois as diferenças 
do que é ser masculino não são salientadas. A identidade de gênero feminina está inserida num processo de repetição pela ação da maternidade, num circuito fechado onde se tem mãe gerando filhas e, novamente, filhas gerando mães.

Voltando nossa atenção para as crianças observadas, meninos e meninas, ao serem tomadas brincando em seu mundo real, nos levaram a inferir um outro mundo paralelo, o da fantasia, que ocorria simultaneamente ao que estávamos observando. As crianças agiam, refletiam, afastavamse das atividades, estavam ou não conectadas com seus parceiros, mas permaneciam, fundamentalmente, conectadas com seus brinquedos, objetos concretos. Seriam as portas para o mundo imaginário? Seria a relação com o brinquedo um meio para a construção de sua auto-imagem?

Ao pensar o mundo imaginário das crianças, a pedagoga Tilde Gallino (1996) apercebe-se da importância dos brinquedos de pelúcia para as crianças. Para ela, tais brinquedos invadiram o cenário do triângulo de Édipo. Sua fala justifica-se porque o objeto transacional, em especial o brinquedo ursinho de pelúcia, estaria imunizado quanto aos tormentos para a definição sexual: castrado/não-castrado, pois não tem gênero definido.

Entretanto, em nossas observações, o tipo de objeto transacional com os quais nos deparamos fazia alusão às diferenças de gênero, pois as crianças brincavam com bonecos- menina, que eram tratados como filhas pelas meninas, e bonecos-menino, que eram tratados como heróis violentos e destruidores pelos meninos. Esse ponto ressalta uma diferença interessante no comportamento de meninas e de meninos.

As meninas vêem o boneco-menina (não presenciamos o uso de bonecos-menino) como uma filha, e se inserem na brincadeira como se fossem um outro personagem: a mãe. Mantêm, assim, o sentido relacional entre pessoas no ato de brincar, expressando sentimentos positivos e amorosos.

Diferenciando seu comportamento, os meninos vêem o boneco-menino, super-herói, enquanto uma projeção de si mesmos, que no sentido relacional enfrenta monstros e inimigos, destruindo-os; portanto, expressando sentimentos negativos.

Acreditamos que as fantasias, enquanto construções subjetivas e imaginárias, são básicas na vida infantil, inclusive na distinção de gênero. Ao articular fantasias e a auto-imagem, a criança está sedimentando as bases de sua identidade. Pudemos perceber tendências de expressões de gênero nas crianças, no exercício do brincar e de inter-relacionar os mundos real e imaginário, em seus movimentos, no uso dos brinquedos, nas ações corporais ou nas expressões emocionais.

A tendência que se manifestou nas meninas nos remete à maternagem, enquanto que os meni- 
nos demonstraram o condicionamento/treinamento dos guerreiros infantis que enfrentavam e destruíam inimigos, dentro do princípio da luta do bem contra o mal.

No mundo do brinquedo, as crianças mais jovens, com menos de 3 anos e seis meses, estiveram como iguais, podiam estar juntas nas mesmas atividades e serviam de modelo umas para as outras, meninos e meninas.

Em relação aos brinquedos, meninos e meninas, a partir de 3 anos e seis meses, estiveram voltados para objetivos essencialmente diferentes, que os distanciavam uns dos outros. Especialmente, os meninos demarcavam no mundo circundante o sentido de pertença ao gênero masculino, evidenciando uma necessidade de afirmar que o menino é diferente e superior à menina. Notamos que os meninos eram desafiados verbalmente, por eles mesmos, a provarem que não eram meninas, fazendo-o por demonstração de força física e de controle das emoções, como valentia e falta de medo.

Pudemos observar que ser menina e estar mais próxima dos meninos significava apanhar, e assim identificamos uma justificativa para que as meninas se afastassem dos meninos. Algumas meninas também expressavam sua agressividade e, desse modo, eram percebidas pelas demais crianças como meninas-menino, queremos dizer, meninas que se igualavam aos meninos. Meninas com tais manifes- tações enfrentavam críticas e conflitos, eram repreendidas e "orientadas" por adultos, que diziam: "Você não deve fazer isso, menina não é assim".

A psicanalista Françoise Dolto (1999, p. 171-174) considera que a agressividade contra outras crianças "deve ser vista como uma busca de contato com elas e não como algo maldoso - se bem que isso faça a criança agredida berrar". Para ela, na expressão da criança não há sentido de bem ou de mal, apenas uma maneira de viver em sociedade, enquanto um exercício entre humanos.

As meninas, em geral, enfrentavam os desafios do processo de amadurecimento e de auto-afirmação manifestando o desejo de se verem como mulheres adultas e se constituírem enquanto mães. Elas permaneceram conectadas e interessadas nas pessoas e, talvez por isso, demonstravam maior sensibilidade e apego, sem medo de expressar emoções, demonstrar fragilidade ou expor suas falhas. Não percebemos demandas para que as meninas demonstrassem méritos corporais, em ações de luta, competição ou mesmo dominação de suas pares.

Os meninos com mais de cinco anos expressaram a busca e manutenção de liderança, pautadas nas atitudes corporais quando precisavam estabelecer domínio sobre os mais fracos, sobre os menores e sobre as meninas.

Também notamos que as crianças com mais de três anos e seis meses 
constituíam o clube do gênero. Grupos de meninas e de meninos permaneciam separados a partir dessa idade: separados espacialmente, separados no mundo concreto do brinquedo, ao escolherem objetos diferentes, separados na construção social.

Observamos que o meio social oferecia oportunidades de forma discriminatória para meninos e meninas. A liberdade de ir e vir não se manifestou eqüitativa em relação aos gêneros. Os meninos podiam sair à rua e brincar nos balanços, correr e interagir entre si e com adultos. As meninas permaneciam reclusas, mantidas em ambientes controlados, proibidas de correr riscos, sendo entendidas enquanto mais frágeis e dignas de maiores cuidados, que eram as justificativas para as limitações impostas às mesmas.

Pudemos identificar que havia um espaço físico delimitado (socialmente) para as meninas, o qual se circunscrevia no lar, ampliando-se ao quintal, no limite da cerca e dos muros no terreno. A escola era entendida como uma extensão dessa área, onde a menina desenvolvia atividades pré-definidas, delimitadas e controladas, tendo em vista comprometimentos futuros de sua formação. As meninas se mostraram mais retraídas. Em ambientes abertos, somente quando se sentiam seguras permitiam-se envolver em brincadeiras ou conversas. Quando acontecia a participação das meninas, isso se dava intensamente, como se um conteúdo represado fosse instan- taneamente liberado.

Os meninos dispunham de espaço muito mais amplo, cheio de emoções e diversidade que, em contrapartida, lhes oferecia mais ris$\cos$ e temores, exigindo maior autoconfiança e espírito de aventura para as constantes descobertas. Percebemos que, de alguma forma, os meninos necessitavam demarcar limites em seu espaço, até como uma maneira de se autoprotegerem, controlando o território sob seu domínio.

Quanto às noções ligadas à sexualidade, as meninas evidenciaram construções mais elaboradas do que os meninos da mesma idade. O maior interesse das meninas nas interações humanas talvez lhes proporcione maior observação e compreensão sobre o que ocorre, subjetivamente, com as pessoas. Além disso, as relações de afeto foram muito mais reveladas nos comportamentos das meninas, tanto para expressar carinho quanto para receber. Os meninos também expressaram comportamentos para receber e dar carinho, mas, de modo ambíguo, se defendiam dos mesmos para não parecerem meninas.

Quando os meninos interviam nas ações ou nas brincadeiras das meninas, eles faziam isso de forma brusca e intrusiva, em atitudes autônomas que expressavam segurança e autoconfiança - "donos da situação". Para efetuarem ações semelhantes intervenção das meninas nas brincadeiras dos meninos - notamos que as meninas necessitavam de autorização 
de um outro, adulto, para fazê-lo. Nesses momentos, entendemos que as meninas expressavam autoconfiança mais reduzida, com receio das conseqüências ou, até mesmo, um comportamento mais comedido, segundo padrões sociais de comportamento vigentes.

\section{CONSIDERAÇÕES FINAIS}

Falar sobre a importância dos(as) professores(as) na construção da identidade de gênero das crianças é importante para nós, enquanto considerações finais. Nossas observações do relacionamento de professores(as) e crianças nos indicaram questões muito sérias e importantes, das quais podemos deduzir contribuições significativas para o contexto educacional.

As dez professoras e o professor, em geral, mostraram-se cuidadores, maternais, dedicados e, enquanto profissionais, percebiam-se socialmente discriminados e inferiorizados por baixos salários e por falta de reconhecimento social. Eram mulheres que trabalhavam para complementar o orçamento familiar, ou homem que subsistia independente, com fonte de renda única.

Sendo o magistério uma função fundamental no contexto educacional, professores(as) oferecem relações significativas e se constituem fontes de identificações para as crianças, devido à proximidade e intensidade dos conta- tos - para muitos, o(a) professor(a) é o primeiro amor fora das relações primárias. Com isso, os(as) professores(as) têm uma função intrínseca na constituição da identidade de gênero. Poderíamos extrapolar a linha de raciocinio de Chodorow para a situação escolar, onde as meninas encontravam na professoramulher alguém igual a elas, que lhes fornecia exemplos a serem seguidos e imitados. A professora representaria uma cuidadora bem sucedida, pois consegue dar atenção e afeto a muitos ao mesmo tempo; é bem aceita e amada pelas meninas. Para os meninos a professora-mulher é alguém para ser amada - um objeto das pulsões sexuais que deve ser negado e superado - o menino não pode ter as mesmas características femininas dela.

O professor-homem está a fazer coisas de mulher, cuidando, ensinando, protegendo. Para as meninas ele se mostra como outra mãe, não há conflito em se inserir sob seu mundo-classe, pois há a continuidade na identificação com uma figura que se expressa feminina, como até então aconteceu. Para os meninos, o professor-homem está no lugar de uma mulher, e representa também a figura de uma mãe. Esse homem, ao assumir tal função, não aprendeu suficientemente as técnicas de luta para negar o 
universo feminino, ele se submeteu ao feminino. Aproximar-se da mãe-homem-professor pode significar um caminho intermediário, onde o universo feminino não necessite ser veementemente negado.

Steve Biddulph (2002, p. 115), que vem se dedicando ao tema de criação de meninos, considera "que um menino querer ser menina vai contra toda a pressão dos colegas e, portanto, deve ser um impulso muito forte". Nesse sentido, uma figura modelo andrógina, cuidadora, mãe-homem-professor, e que não evidencie o papel masculino preponderante, possibilitaria uma alternativa de acomodação para tal impulso, com a redução da pressão social externa. A figura do(a) professor(a) se constitui enquanto o poder que autoriza e demonstra como proceder. Um professorhomem que evidencie o papel masculino preponderante representaria um modelo que dissolve questões ambíguas para os meninos, dando-lhes referenciais para identificação, que une carinho, força e exemplo de superação e negação do mundo feminino. Para as meninas esse professor-homem representaria outro homem para ser amado e para ser conquistado, submetendo-se e correspondendo ao aconchego de suas expressões de carinho. Lembramos da afirmação feita por uma das professoras com as quais mantivemos contato. Ela dizia que os meninos são mais carinhosos e demonstrava maior aproximação em relação a eles. Sue Askew e Carol Ross (1991) também se depararam com uma diferença de atenção dos(as) professores(as) para meninos e meninas, afirmando que os meninos recebem mais atenção:

Também é importante examinar as coisas que poderiam estar afetando negativamente a educação das meninas, tais como a quantidade e o tipo de atenção que elas recebem do professor nas classes mistas. (ASKEW e ROSS, 1991, p. 11).

O psicólogo William Pollack, que concentrou seus estudos em meninos, sugere que mesmo recebendo atenção diferenciada, ela pode estar acontecendo por uma compreensão inexata dos meninos:

Tendo uma visão restrita dos meninos e deixando de reconhecer o lado empático criativo e carinhoso de muitos deles, creio que alguns professores - embora inconscientemente - comprometem seriamente seu desenvolvimento emocional e educacional, caso eles não se encaixem necessariamente nas regras sociais antigas e estereotipadas sobre como devem se comportar, aprender $e$ crescer. (POLLACK, 1999, $p$. 279).

Em nenhum momento estivemos 
avaliando ou comparando o desempenho escolar entre meninos e meninas, mas estas últimas reflexões nos remetem a pensar, enquanto educadores, sobre problemas de fracasso escolar e de suas relações ou derivações da forma de relacionamento entre professores(as) e alunos(as) mediatizadas por gênero.

Nas discussões de gênero, especialmente aquelas oriundas de Chodorow (1990) e Boris (2000), há consenso quanto à importância das fases da infância para a construção das relações de gênero e sua sedimentação no ser humano. Estabelecendo uma analogia entre os trabalhos de Anna Freud e de Sigmund Freud, é possível perceber que ela não se satisfez com as referências ao conteúdo da infância feitas pelo psicanalista, e, diante disso, aproximou-se diretamente das crianças. Acreditamos que, na aproximação do conceito gênero ao desenvolvimento infantil, devemos proceder da mesma maneira. É possível o desenvolvimento de trabalho prático, direto com as crianças, que seja elaborado tanto do ponto de vista clinico quanto do ponto de vista educacional.

Desse modo, nossa contribuição referenda que as crianças da faixa etária abaixo de 3 anos e seis meses não fazem diferenças de gênero importantes. Nos relacionamentos, elas permanecem juntas ao brincar e escolhem brinquedos aleatoriamente. Acreditamos que até essa faixa etária temos oportunidade para desenvolver atividades psico-pedagógicas que mantenham a universalidade dos brinquedos para ambos os sexos, favorecendo a interatividade espontânea entre meninos e meninas. Tal prática pode ser mantida até os 5 anos de idade.

Conforme nossa pesquisa, a partir dos cinco anos de idade os meninos estiveram muito ativos fisicamente, expressando-se com agressividade; as meninas da mesma faixa etária estiveram mais voltadas para comportamentos de sensibilidade e afabilidade. Quanto aos meninos, acreditamos ser uma época adequada para empregar alternativas pedagógicas que estimulem sua sensibilidade e percepção das figuras humanas, tendo sua aptidões melhor exploradas. Para as meninas dessa fase, recomendamos serem incentivadas atividades que reforcem sua autoconfiança, tais como jogos competitivos e exploração de brinquedos lógicos ou construtivos.

As ações propostas contrapõem rígidas demarcações de gênero com as quais nos deparamos em ambientes pedagógicos: o que é permitido ou adequado para os meninos e o que é permitido ou adequado para as meninas, classificando-se por dicotomia. Desse modo, oportunidades para o desenvolvimento de capacidades além de expressões emocionais estarão contempladas em outro paradigma que favoreça a relação amistosa entre homens e mulheres, com repercussão significativa para a 
vida adulta - familiar e social ampla.

No que se refere a essa relação amistosa, que compreende, inclusive, as relações do indivíduo consigo mesmo e com o seu meio de vida, transcrevemos uma fala muito expressiva e desencadeadora, feita por JeanClaude Liaudet ao referir-se a Françoise Dolto:

No exercício de sua profissão, Fraçoise Dolto sempre se proibiu ter um projeto sobre as crianças que tratava. Neste sentido, ela distinguiu sempre claramente o seu papel do de um pai. Enquanto psicanalista, a opção de vida de uma criança não lhe dizia respeito. Que esta prefira ser bizarra, que fique louca ou débil, de sexo incerto, pouco lhe importava se ela tivesse conseguido encontrar um equilibrio para si mesma e nas relações com seu meio de vida: se ela funcionava bem, não achava que tivesse algo a dizer, respeitava a orientação. (LIAUDET, 2000, p. 11).

Essa é uma posição que pode ser adotada do ponto de vista ético-clínico, pois na relação entre criança e psicanalista, o profissional deve respeitar as escolhas e a liberdade de seu "paciente". Porém, afirmamos que para a educação tal posição deve ser negada: não pode ser uma posição do (a) educador (a) frente ao mundo particular da criança ou no que se refere às reflexões da sociedade e, principalmente, não pode ser adotada em tudo aquilo que seja remetido ao mundo da escola. Na condição dos educadores, não consideramos uma neutralidade de influências, seja em sua relação com as crianças, seja nos conteúdos educacionais propostos, certamente, temas que são discutidos amplamente.

Em nossa reflexão abordamos o tema gênero mediado por conteúdo teórico que se aproximou do referencial psicodinâmico sem, no entanto, enfocar questões de ordem clínica. Neste trabalho, a educação sempre foi o alvo primordial e, portanto, ao concluirmos, afirmamos nossa defesa de ações educacionais próativas, voltadas para as crianças das etapas pré-escolares, naquilo que concerne à educação de gênero e socialização secundária.

Ao vislumbramos nossas próprias afirmações nos damos conta de que, de fato, estamos propondo uma reaproximação de teorias psicodinâmicas com a educação. Embora nossos argumentos estivessem restritos aos construtos freudianos, ou decorrentes destes, nos questionamentos e elaborações de Nancy Chodorow, compreendemos que as abordagens psicodinâmicas decorrentes das postulações freudianas, potencialmente, podem colaborar com a educação. No entanto, ao afirmarmos tal potencialidade, entendemos que certo esforço deva ser empreendido nos cenários de discussão e produção acadêmica, para que a educação possa ser beneficiada com tais conhecimentos. 
logia: caminhos e desafios. São Paulo: Thompson Pioneira, 2000.

\section{REFERÊNCIAS}

ASKEW, S.; ROSS, C. Los chicos no lloran. Barcelona: Paidós Educador, 1991.

BIDDULPH, S. Criando meninos. São Paulo: Fundamento, 2002.

BORIS, G. J. B. Falas masculinas ou ser homem em Fortaleza: múltiplos recortes da construção da subjetividade masculina na contemporaneidade. Tese (Doutorado em Sociologia) - Universidade Federal do Ceará, Fortaleza, 2000.

CHODOROW, N. Psicanálise da maternidade: uma crítica a Freud a partir da mulher. Rio de Janeiro: Rosa dos Tempos, 1990.

. The reproduction of mothering. California: University of California, 1978.

Feminism and psychoanalytic theory. London: Polity Press, 1989.

DOLTO, F. As etapas decisivas da infância. São Paulo: Martins Fontes, 1999.

FREUD, S. Obras psicológicas de S. Freud. São Paulo: Imago, 1998.

GALLINO, T. O mundo imaginário das crianças: no princípio era o ursinho. Porto: Civilização, 1996.

GUIMARÃES, I. R. F. Pode o conceito de gênero mudar a compreensão do desenvolvimento psicossexual?. Entretexto entresexo, São Paulo, Unicamp, out. 1997.

POLLACK, W. Meninos de verdade: conflitos e desafios. São Paulo: Alegro, 1999.

REY, G. Pesquisa qualitativa em psico-

Olhar de professor, Ponta Grossa, 7(1): 85-101, 2004. $\overline{101}$ 